\title{
O SHOW DA QUÍMICA: MOTIVANDO O INTERESSE CIENTÍFICO
}

Agnaldo Arroio

Departamento de Artes e Comunicação, Centro de Educação e Ciências Humanas, Universidade Federal de São Carlos, 13560-970 São Carlos - SP

Káthia M. Honório, Karen C. Weber, Paula Homem-de-Mello, Maria Teresa do Prado Gambardella e Albérico B. F. da Silva*

Departamento de Química e Física Molecular, Instituto de Química de São Carlos, Universidade de São Paulo, CP 780 , 13560-970 São Carlos - SP

Recebido em 14/12/04; aceito em 19/5/05; publicado na web em 1/12/05

\begin{abstract}
THE CHEMISTRY SHOW: MOTIVATING THE SCIENTIFIC INTEREST. The aim of this article is to provide the understanding of the chemical world that underlies everything around us by introducing basic chemical concepts and their everyday applications. The specific topics presented were selected according to their relevance and their ability to be presented as an exhibition. This format is based on the visual effects that help the public to see abstract descriptions in a concrete form. In addition, a soundtrack is used to stimulate the affective intelligence and relax the public. According to the results obtained here, we can conclude that chemical demonstrations, combined with music, help the presentation of scientific topics and motivate and facilitate the "chemistry communication".
\end{abstract}

Keywords: chemical demonstrations; informal education; chemistry communication.

\section{INTRODUÇÃO}

As Ciências Básicas (Química, Física e Matemática) soam como carreiras que não despertam interesses nos jovens por diferentes razões: ou porque nossa sociedade ainda valoriza apenas a tríade Medicina-Engenharia-Direito, ou porque o desenvolvimento científico ainda não é visto como um tema nacional como a Economia e a Política, ou mesmo porque ser professor de Ciências está vinculado à educação, cujos valores e importância para o desenvolvimento e a soberania de uma nação não são priorizados. Enfim, as razões podem ser as mais diversas possíveis.

A maneira como a Química é abordada nas escolas pode ter contribuído para a difusão de concepções distorcidas dessa ciência, uma vez que os conceitos são apresentados de forma puramente teórica (e, portanto, entediante para a maioria dos alunos), como algo que se deve memorizar e que não se aplica a diferentes aspectos da vida cotidiana.

Os meios de comunicação também podem colaborar com esta distorção. Freqüentemente podem ser vistas na televisão propagandas oferecendo produtos que por serem naturais "não contêm química" e, assim, são mais saudáveis. Em outros momentos, a química é apresentada como a grande vilã contra o meio ambiente, pois dejetos químicos despejados nos rios e fumaças nas chaminés de indústrias são as principais imagens associadas à Química como fonte de poluição.

Não é novidade que os jovens não se interessem pela Química e que tenham esta visão distorcida, chegando a considerar que essa ciência não faz parte de suas vidas. Desta forma, verifica-se a necessidade da utilização de formas alternativas relacionadas ao ensino de química, com o intuito de despertar o interesse e a importância dos conceitos químicos presentes nos currículos escolares.

Babin e Koloumdjian ${ }^{1}$, em suas pesquisas com jovens frente à realidade da comunicação proveniente dos avanços da tecnologia, confirmam a hipótese de que "a invasão das mídias e o emprego de

*e-mail: alberico@iqsc.usp.br aparelhos eletrônicos na vida cotidiana modelam progressivamente um outro comportamento intelectual e afetivo nos jovens". "Eles estão em outra", afirmaram os autores, e isto significa outras necessidades, outras percepções, outros relacionamentos. A influência das mídias entre os jovens faz com que estes mudem seus padrões de referência, alterem suas relações consigo mesmos e com as circunstâncias sociais em geral, criando outras necessidades, envolvimentos, modelos de conduta e, porque não dizer, outros problemas que algumas escolas não estão preparadas para enfrentar.

Devido ao baixo interesse pelos cursos de Ciências Básicas nos últimos vestibulares, diferentes formas de motivar o interesse por temas científicos ainda nas escolas de ensino médio e fundamental foram estudadas. Com o intuito de divulgar de maneira informal a Química por meio de experimentos, bem como despertar a curiosidade e incentivar o interesse dos alunos por esta nobre área, foi elaborado o "Show de Química com Música".

A escolha por esta modalidade (show de química com música) deve-se ao fato da força da linguagem audiovisual conseguir dizer muito mais do que captamos, chegando simultaneamente por muito mais caminhos do que conscientemente percebemos, fazendo com que encontremos dentro de nós uma repercussão em imagens básicas, centrais, simbólicas, arquetípicas, com as quais nos identificamos, ou que se relacionam conosco de alguma forma, segundo Arroio e Giordan².

É consenso que a experimentação desperta interesse entre os alunos, independente do nível de escolarização ${ }^{3}$. Os experimentos demonstrativos ajudam a enfocar a atenção do estudante nos comportamentos e propriedades de substâncias químicas e auxiliam, também, a aumentar o conhecimento e a consciência do estudante de química ${ }^{4}$. Resgatando os experimentos demonstrativos de Shakhashiri ${ }^{5,6}$ e a idéia da divulgação da Química através de shows como os do grupo "Química em Ação", coordenado pelo saudoso Prof. José Atílio Vanin 7 que atingiu um público estimado em 50 mil pessoas através de três centenas de apresentações, buscamos preparar uma apresentação visando a divulgação da Química, principalmente para alunos do ensino médio, através de recursos visu- 
ais e sonoros da linguagem audiovisual, que fazem parte do universo destes alunos, estabelecendo assim uma comunicação mais efetiva através da sensibilização de suas atenções.

Durante a realização de experimentos demonstrativos, o conhecimento do professor sobre comportamento e propriedades do sistema químico, e a forma como o professor manipula os sistemas químicos funcionam como um modelo não somente de técnica, mas também de atitude. Experimentos demonstrativos envolvem geralmente maior participação dos estudantes e maior confiança em questões e sugestões tais como "O que acontecerá se você adicionar mais de ...?”. Em princípio, e na prática, todo experimento demonstrativo é uma situação em que os professores podem transportar suas atitudes sobre a base experimental de química e podem, deste modo, motivar os estudantes a realizarem experimentações adicionais, além de induzí-los a relacionar teoria e experimentação.

No processo de ensino-aprendizagem de química, professores e estudantes tomam parte em uma série complexa de atividades intelectuais. Estas atividades podem ser organizadas em uma hierarquia que indica sua complexidade crescente: observar fenômenos e aprender fatos; entender modelos e teorias; desenvolver habilidades de raciocínio e examinar a epistemologia química.

Essa hierarquia constitui a estrutura básica envolvida na aplicação de experimentos demonstrativos no ensino de química ${ }^{6}$. Evidentemente, os experimentos demonstrativos não devem ser considerados como substitutos para as aulas experimentais. No laboratório, os estudantes podem trabalhar com substâncias químicas e diferentes equipamentos e fazer suas próprias descobertas por ação mediada pelo professor, participando ativamente do processo de aprendizagem. Durante a realização dos experimentos demonstrativos, os alunos testemunham mudanças químicas que são manipuladas pelo professor. Portanto, o professor controla o experimento e explica os objetivos de cada passo e ambos os tipos de instrução são partes integrantes da educação que deve ser oferecida aos estudantes ${ }^{5}$.

Em geral, as pessoas foram acostumadas a pensar e agir baseando-se no raciocínio lógico, linear e seqüencial, deixando de lado emoções, intuição, criatividade e capacidade de ousar soluções diferentes. Sendo assim, utilizam muito mais o hemisfério esquerdo do cérebro, considerado racional, deixando de usufruir os benefícios contidos no hemisfério direito, tais como imaginação, criatividade, generalidade, visão global, capacidade de síntese e facilidade de memorizar, dentre outras. Porém, através de técnicas variadas, pode-se estimular o lado direito do cérebro e buscar a integração entre os dois hemisférios, equilibrando o uso de nossas potencialidades, de acordo com Carneiro ${ }^{8}$.

A linguagem e a memória desenvolvem-se conjuntamente, uma se apoiando na outra. A aprendizagem relaciona-se com a linguagem por meio dos conteúdos que a memória traz à tona através da fala. Segundo Vygotsky ${ }^{9}$, existe uma inter-relação fundamental entre pensamento e linguagem, um proporcionando recursos ao outro. Desta forma, a linguagem tem um papel essencial na formação do pensamento e do caráter do indivíduo.

O uso de música apropriada, que diminui o ritmo cerebral, também contribui para que haja equilíbrio no uso dos hemisférios cerebrais. Músicas para relaxamento têm a mesma frequiência que um feto escuta e nos direciona automaticamente ao lado direito do cérebro, fazendo com que as informações sejam gravadas na memória de longo prazo. Portanto, o indivíduo encontra-se motivado e, conseqüentemente, muito mais receptivo à aprendizagem, pois sua inteligência afetiva está sendo estimulada mediante sensações de prazer ${ }^{8}$.

A utilização de experimentos demonstrativos associados à música, que estimulam tanto a percepção visual quanto a auditiva, aliados a uma divulgação da pesquisa científica, abordados de for- ma bastante simples e didática, são boas ferramentas para a desmistificação da Ciência no ensino médio e fundamental. Desta forma, neste trabalho, alguns experimentos demonstrativos foram apresentados a alunos de ensino médio e superior, juntamente com temas musicais, com o objetivo de avaliar o impacto deste tipo de atividade na divulgação da Química.

\section{METODOLOGIA}

O projeto "Show de Química com Música" foi desenvolvido por alunos do programa de Pós-Graduação do IQSC/USP, com apoio da Comissão de Cultura e Extensão (CCEx) do IQSC/USP. Na primeira fase do projeto, os experimentos foram apresentados em três ocasiões distintas: recepção aos alunos ingressantes do Curso de Química do IQSC em 2003; visita de alunos do ensino médio ao IQSC, como parte do programa Casa Aberta da USP; III Feira das Profissões da USP - Campi Interior, realizada em São Carlos.

Após as apresentações, um questionário de avaliação das atividades foi aplicado aos alunos com a finalidade de obter a opinião dos mesmos e, assim, aprimorar as demonstrações, buscando sempre maior aproximação com os interesses dos alunos. Um total de sete experimentos demonstrativos foi utilizado nas três apresentações citadas acima: tornado, decomposição da água oxigenada, reação química "ativada" pela voz, "garrafa azul”, reação de BriggsRauscher, reação colorida e reação simulando a chuva ácida. A seguir, cada um dos experimentos realizados é descrito em maior detalhe.

\section{Experimento 1. Tornado}

A reação chamada de tornado é um equilíbrio de precipitação no qual duas soluções - A ( 2 g de $\mathrm{Hg}\left(\mathrm{NO}_{3}\right)_{2}$ e $100 \mathrm{~mL}$ de $\left.\mathrm{HNO}_{3}\right)$ e B (16 $\mathrm{g}$ de $\mathrm{KI}$ e $100 \mathrm{~mL}$ de $\mathrm{H}_{2} \mathrm{O}$ ) - são misturadas levando à formação de um precipitado laranja, como está representado na Equação 1

$$
\begin{aligned}
& \mathrm{Hg}^{2+}+2 \mathrm{I} \rightleftarrows \mathrm{HgI}_{2} \\
& \mathrm{HgI}_{2}+2 \mathrm{I} \rightleftarrows \mathrm{HgI}_{4}^{2-}
\end{aligned}
$$

O precipitado laranja inicial é o produto cineticamente favorecido $\left(\mathrm{HgI}_{2}\right)$, o qual apresenta coloração laranja e é insolúvel. O íon $\mathrm{HgI}_{4}^{-2}$ é termodinamicamente favorecido, o qual é incolor e solúvel. Sendo assim, um equilíbrio entre estas duas espécies (formação do precipitado seguido pela dissolução do mesmo) é alcançado e, devido à agitação do sistema, um efeito semelhante a um tornado pode ser observado 6 . Esta reação foi acompanhada pela "Marcha" de "O Quebra-Nozes", de Tchaikovsky, escolhida por apresentar alternância de volumes altos e baixos e dar a idéia de idas e voltas como em um tornado.

\section{Experimento 2. Decomposição da água oxigenada}

A segunda reação apresentada foi a decomposição da água oxigenada, que aborda conceitos sobre velocidade de uma reação química e utilização de catalisadores. A velocidade de uma reação química depende de numerosos fatores, como, por ex., concentrações dos reagentes, temperatura, catalisadores, etc. Um catalisador pode aumentar notavelmente a velocidade de uma reação química sem que ele próprio se altere quimicamente. Os catalisadores apresentam grande importância na indústria química, possibilitando ou acelerando reações que não seriam utilizáveis, na prática, sem a presença deles. São mais importantes ainda em reações bioquímicas, pois sem catalisadores as reações essenciais para o metabolis- 
mo ocorreriam tão vagarosamente que o mundo como nós conhecemos não existiria ${ }^{10}$.

Neste experimento, observa-se a formação de espuma em grande quantidade, que pode ser colorida com a adição de anilinas. A espuma é um tipo de colóide em que um gás (neste caso o oxigênio) se encontra disperso em um líquido, isto é, tem-se um grande número de bolhas de gás espalhadas em uma superfície líquida com uma fina película de líquido separando as bolhas de gás entre si. A formação da espuma pode ser facilitada pela presença de detergentes que, à semelhança dos sabões, facilitam a formação de colóides do tipo da espuma. O presente experimento, muito simples, permite exemplificar esses conceitos de forma visual, o que pode auxiliar muito na compreensão dos conceitos discutidos.

Após a adição de um catalisador, ocorre a reação de decomposição da água oxigenada, representada pela Equação 2

$2 \mathrm{H}_{2} \mathrm{O}_{2} \rightarrow 2 \mathrm{H}_{2} \mathrm{O}+\mathrm{O}_{2} \uparrow$

Esta é uma reação cuja velocidade é acelerada utilizando catalisadores. Neste caso, o catalisador utilizado foi o iodeto de potássio, por meio do íon iodeto. As reações envolvendo o íon iodeto são apresentadas na Equação 3

$\mathrm{H}_{2} \mathrm{O}_{2}+\mathrm{I}^{-} \rightarrow \mathrm{H}_{2} \mathrm{O}+\mathrm{OI}^{-}$

$\mathrm{H}_{2} \mathrm{O}_{2}+\mathrm{OI}^{-} \rightarrow \mathrm{H}_{2} \mathrm{O}+\mathrm{I}^{-}+\mathrm{O}_{2}$

O experimento foi realizado em provetas de $500 \mathrm{~mL}$ e em cada proveta foram colocados $20 \mathrm{~mL}$ de $\mathrm{H}_{2} \mathrm{O}_{2}, 10 \mathrm{~mL}$ de detergente e algumas gotas de anilina (utilizamos uma coloração diferente para cada proveta). A seguir, foram adicionados $2 \mathrm{~g}$ de iodeto de potássio e, então, a decomposição se processou, gerando espuma de diferentes cores suficiente para preencher todo o volume da proveta.

A música escolhida para esta reação foi "Uma Noite sobre o Monte Calvo“, de Mussorgsky. Esta música propicia uma sensação de catástrofe e explosão, oferecendo um clima apropriado para a "erupção" da espuma formada.

\section{Experimento 3. Reação química "ativada" pela voz}

A reação química "ativada" pela voz envolve óxidos ácidos. Os óxidos ácidos são formados por não metais (sendo neste caso compostos geralmente gasosos) ou por metais com número de oxidação elevado, como por ex. $\mathrm{CrO}_{3}, \mathrm{MnO}_{3}, \mathrm{Mn}_{2} \mathrm{O}_{7}$, etc. Estes ácidos são compostos moleculares e, em geral, solúveis em água. Nos óxidos ácidos, o oxigênio encontra-se ligado a um não metal através de ligações covalentes. Tais óxidos caracterizam-se por produzirem um ácido ao reagirem com água. A formação do ácido pode ser visualizada pela adição de um indicador.

Neste experimento foram adicionadas 4 gotas do indicador azul de bromotimol a $25 \mathrm{~mL}$ de álcool etílico em um erlenmeyer. A seguir, acrescentou-se uma gota de solução $1 \mathrm{~mol} \mathrm{~L}^{-1}$ de $\mathrm{NaOH}$. A solução obtida apresentou uma coloração azulada e foi pedido aos alunos que pronunciassem algumas palavras no recipiente contendo a solução. O resultado observado após algumas palavras era a mudança na coloração da solução, ou seja, a cor passou de azul para verde ${ }^{10}$.

A explicação para este fato é a seguinte: o azul de bromotimol é um indicador ácido-base que apresenta as seguintes colorações para faixas de pH: ácido (amarelo), neutro (verde) e básico (azul). Quando o hidróxido de sódio (base) é adicionado à solução contida no erlenmeyer, esta se torna básica. Durante o processo da respiração, quando expiramos liberamos boa quantidade de gás carbônico que é um óxido ácido. Este gás em meio aquoso produz ácido carbônico. Quando alguma palavra é pronunciada bem perto do erlenmeyer injetamos grande quantidade de ar contendo gás carbônico e este, em contato com a água, produz ácido carbônico conforme a Equação 4

$$
\mathrm{CO}_{2}+\mathrm{H}_{2} \mathrm{O} \rightarrow \mathrm{H}_{2} \mathrm{CO}_{3}
$$

(gás carbônico) (ácido carbônico)

A produção desse ácido vai neutralizando a solução que, inicialmente, é básica. O efeito visual da neutralização é a solução mudar sua coloração para verde. A equação de neutralização é dada por:

$$
\begin{aligned}
& \mathrm{H}_{2} \mathrm{CO}_{3}+\mathrm{NaOH} \rightarrow \mathrm{NaHCO}_{3}+\mathrm{H}_{2} \mathrm{O} \\
& \text { (ácido carbônico) (hidróxido de sódio) (bicarbonato de sódio) }
\end{aligned}
$$

O experimento foi acompanhado pelo "Entreato I" e pela "Dança Boêmia", ambos trechos de "Carmen" de Bizet.

\section{Experimento 4. "Garrafa azul"}

Um outro experimento realizado foi o da "garrafa azul", no qual são abordados conceitos envolvendo óxido-redução, ação de catalisadores e dissolução do ar atmosférico em água. Neste experimento, uma garrafa de plástico transparente é parcialmente preenchida com um líquido de coloração rósea. Quando o líquido é agitado, uma coloração azul é adquirida. Após permanecer em repouso a coloração azul muda para rosa. Este ciclo rosa-azul-rosa, obtido pela seqüência agitação/imobilidade/agitação, pode ser repetido dezenas de vezes antes que o líquido se inutilize.

O procedimento para realização deste experimento é o seguinte: adicionar $180 \mathrm{~mL}$ de água destilada e $3,5 \mathrm{~g}$ de hidróxido de sódio na garrafa e agitar até dissolver completamente o hidróxido; a seguir, dissolver 6,0 g de glicose na solução de hidróxido de sódio e, então, acrescentar 70 gotas de azul de metileno $0,1 \%$.

A glicose em meio alcalino é lentamente oxidada pelo oxigênio dissolvido em solução, formando ácido glicólico, conforme a Equação 6

$$
\begin{array}{r}
\mathrm{CH}_{2} \mathrm{OH}-\mathrm{CHOH}-\mathrm{CHOH}-\mathrm{CHOH}-\mathrm{CHOH}-\mathrm{CHO}+{ }^{1} / 2 \mathrm{O}_{2} \rightarrow \\
\mathrm{CH}_{2} \mathrm{OH}-\mathrm{CHOH}-\mathrm{CHOH}-\mathrm{CHOH}-\mathrm{CHOH}-\mathrm{COOH}
\end{array}
$$

Na presença de hidróxido de sódio, o ácido é convertido em gliconato de sódio. $\mathrm{O}$ azul de metileno catalisa a reação porque atua como um agente de transferência de oxigênio. Ao oxidar a glicose, o azul de metileno reduz-se a leuco-metileno, tornando-se incolor. O leuco-metileno se re-oxida rapidamente enquanto houver oxigênio no sistema e a solução volta a se tornar azul ${ }^{10}$.

A música que acompanhou este experimento foi "O Fantasma da Ópera", de Webber, que foi utilizada para incentivar a dinâmica do experimento.

\section{Experimento 5. Reação de Briggs-Rauscher}

Reações oscilantes estão entre as reações demonstrativas mais fascinantes dentro da química. Nas duas reações apresentadas neste trabalho, uma mistura de soluções apresenta uma seqüência de cores que se repete periodicamente. Este tipo de reação é uma excelente ferramenta a ser utilizada quando se deseja atrair a atenção dos alunos, pois cria uma expectativa pela aparição de uma nova cor, despertando o interesse em descobrir o que ocorre durante estes experimentos.

As oscilações de uma reação oscilante são guiadas pela diminuição na energia livre da mistura, de forma a atingir o equilíbrio. Esta diminuição na energia é o que guia todas as reações químicas, mas nem todas as reações apresentam oscilações. $\mathrm{O}$ que faz com que certas reações apresentem este comportamento peculiar é o caminho adotado pela reação para chegar ao equilíbrio, ou seja, depende dos mecanismos da reação. $\mathrm{O}$ caminho que a reação segue 
determina como as concentrações dos componentes mudam com o decorrer da reação. Quanto mais complexo é o caminho de uma reação, mais complexas podem ser as variações nas concentrações dos componentes da mistura.

Os mecanismos das reações oscilantes apresentam pelo menos três características em comum. Primeiro, quando a oscilação ocorre, o sistema está longe do equilíbrio e o ciclo se repete conforme a energia diminui. Segundo, a queda de energia pode se dar por, pelo menos, dois caminhos diferentes, e a reação procede alternando periodicamente um caminho e outro. Terceiro, um desses caminhos produz um intermediário que o outro caminho consome. Quando a concentração desse intermediário é baixa, a reação segue o caminho que o produz. Se a concentração é alta, a reação segue o outro caminho. Assim a reação repetidamente muda de um caminho para o outro. Essas reações são ditas auto-catalíticas.

A reação de Briggs-Rauscher é um exemplo de reação oscilante e foi realizada nas três ocasiões citadas. Neste experimento três soluções incolores são combinadas em um béquer. A solução resultante, sob agitação contínua, torna-se âmbar, a seguir azul e, finalmente, incolor novamente. Esta seqüência de mudanças de cores se repete dentro de um intervalo de, aproximadamente, $15 \mathrm{~s}$. O período da oscilação gradualmente aumenta e, após alguns minutos, a coloração azul torna-se definitiva ${ }^{5}$.

Em um béquer de $1 \mathrm{~L}$, são adicionados $500 \mathrm{~mL}$ da primeira solução que consiste de água oxigenada $3 \%, 250 \mathrm{~mL}$ da segunda solução, formada por iodato de potássio (14,5 g) dissolvidos sob agitação e aquecimento em $200 \mathrm{~mL}$ de água destilada e $4 \mathrm{~mL}$ de $\mathrm{H}_{2} \mathrm{SO}_{4} 6 \mathrm{~mol} \mathrm{~L}^{-1}$, solução esta que a seguir é diluída a $250 \mathrm{~mL}$, e $250 \mathrm{~mL}$ da terceira solução, que é obtida com o seguinte procedimento: dissolver $5,2 \mathrm{~g}$ de ácido malônico $\left(\mathrm{CH}_{2}\left(\mathrm{CO}_{2} \mathrm{H}\right)_{2}\right)$ e $1,1 \mathrm{~g}$ de sulfato de manganês (II) monoidratado em $200 \mathrm{~mL}$ de água destilada; colocar $0,1 \mathrm{~g}$ de amido em 2,5 mL de água destilada e agitar até obter uma goma. Dissolver sob aquecimento e agitação esta goma em $25 \mathrm{~mL}$ de água destilada fervente; adicionar a solução de amido à solução de ácido malônico e sulfato de manganês e diluir a $250 \mathrm{~mL}$ com água destilada.

Quando as soluções são misturadas, os íons iodato reagem com a água oxigenada produzindo HOI (reação catalisada pelo manganês), que é parcialmente reduzido a I- pela água oxigenada. O HOI reage com o I- formando $\mathrm{I}_{2}$ e este reage lentamente com o ácido malônico. Este processo é representado nas Equações 7

$$
\begin{aligned}
& 2 \mathrm{H}_{2} \mathrm{O}_{2}+\mathrm{IO}_{3}^{-}+\mathrm{H}^{+} \rightarrow \mathrm{HOI}+2 \mathrm{O}_{2}+2 \mathrm{H}_{2} \mathrm{O} \\
& \mathrm{H}_{2} \mathrm{O}_{2}+\mathrm{HOI} \rightarrow \mathrm{I}^{-}+\mathrm{O}_{2}+\mathrm{H}^{+}+\mathrm{H}_{2} \mathrm{O} \\
& \mathrm{I}^{-}+\mathrm{HOI}+\mathrm{H}^{+} \rightarrow \mathrm{I}_{2}+\mathrm{H}_{2} \mathrm{O} \\
& \mathrm{I}_{2}+\mathrm{CH}_{2}\left(\mathrm{CO}_{2} \mathrm{H}\right)_{2} \rightarrow \mathrm{ICH}\left(\mathrm{CO}_{2} \mathrm{H}\right)_{2}+\mathrm{H}^{+}+\mathrm{I}^{-}
\end{aligned}
$$

As Equações abaixo indicam o efeito catalítico do manganês:

$$
\begin{aligned}
& \mathrm{HIO}_{2}+\mathrm{IO}_{3}^{-}+\mathrm{H}^{+} \rightarrow 2 \mathrm{IO}_{2}^{-}+\mathrm{H}_{2} \mathrm{O} \\
& \mathrm{IO}_{2}^{-}+\mathrm{Mn}^{2+}+\mathrm{H}_{2} \mathrm{O} \rightarrow \mathrm{Mn}(\mathrm{OH})^{2+}+\mathrm{HIO}_{2} \\
& \mathrm{Mn}(\mathrm{OH})^{2+}+\mathrm{H}_{2} \mathrm{O}_{2} \rightarrow \mathrm{Mn}^{2+}+\mathrm{H}_{2} \mathrm{O}+\mathrm{HOO}^{\circ} \\
& 2 \mathrm{HOO}^{\cdot} \rightarrow \mathrm{H}_{2} \mathrm{O}_{2}+\mathrm{O}_{2} \\
& 2 \mathrm{HIO}_{2} \rightarrow \mathrm{IO}_{3}^{-}+\mathrm{HOI}+\mathrm{H}^{+}
\end{aligned}
$$

A solução torna-se de coloração âmbar quando o $\mathrm{I}_{2}$ é produzido. A solução apresentará coloração azul escura quando a concentração de $\mathrm{I}^{-}$for superior à concentração de HOI. A alteração de cores se dá até que todo o ácido malônico seja consumido.

Durante a realização deste experimento, a música utilizada foi "Sobre o Danúbio Azul", de Strauss. A famosa valsa remete o espectador ao ambiente de um baile, onde se pode observar o rodopi- ar e a variação de cores dadas pelos vestidos. Além disto, o nome da música "Sobre o Danúbio Azul" faz alusão à cor mais intensa assumida pelo sistema (azul).

\section{Experimento 6. Reação colorida}

A outra reação oscilante realizada envolve a variação gradual da cor de uma solução, colocada em um béquer sob agitação. Esta variação de cores vai de verde a azul e, então, a violeta e, finalmente, a vermelho. A coloração repentinamente retorna à coloração verde e o ciclo se repete por cerca de 20 vezes $^{5}$.

Para isso, acrescenta-se a uma solução incolor (solução A), uma solução amarela (solução B), resultando em uma solução âmbar que se torna incolor após $1 \mathrm{~min}$. A seguir, uma solução amarela (solução C) é adicionada, seguida por $15 \mathrm{~mL}$ de uma solução vermelha (solução de ferroína), produzindo uma solução verde. A solução A é obtida dissolvendo-se $9,50 \mathrm{~g}$ de bromato de potássio em $250 \mathrm{~mL}$ de água destilada. A solução B consiste da dissolução de 8 g de ácido malônico e $1,75 \mathrm{~g}$ de brometo de potássio em $250 \mathrm{~mL}$ de água destilada. Para obter a solução C é necessário dissolver 2,65 g de nitrato de amônio cério (IV) em $250 \mathrm{~mL}$ de solução de ácido sulfúrico $2,7 \mathrm{~mol} \mathrm{~L}^{-1}$. Já a solução de ferroína é preparada pela dissolução de $0,165 \mathrm{~g}$ de sulfato de ferro heptaidratado e $0,23 \mathrm{~g}$ de fenantrolina em $50 \mathrm{~mL}$ de água destilada.

O mecanismo dessa reação oscilante pode ser dividido em dois processos. Um processo (Processo A) é representado pela reação global esquematizada na Equação 9

$\mathrm{BrO}_{3}^{-}+5 \mathrm{Br}^{-}+6 \mathrm{H}^{+} \rightarrow 3 \mathrm{Br}_{2}+3 \mathrm{H}_{2} \mathrm{O}$

Esta reação representa a redução dos íons bromato por íons brometo através de uma série de transferências de oxigênio (reduções de dois elétrons). Esta reação ocorre quando são misturadas as soluções A e B. A coloração âmbar é devida ao $\mathrm{Br}_{2}$. Esta cor desaparece quando o $\mathrm{Br}_{2}$ reage com o ácido malônico, como representado pela Equação 10

$\mathrm{Br}_{2}+\mathrm{CH}_{2}\left(\mathrm{CO}_{2} \mathrm{H}\right)_{2} \rightarrow \mathrm{BrCH}\left(\mathrm{CO}_{2} \mathrm{H}\right)_{2}+\mathrm{Br}^{-}+\mathrm{H}^{+}$

Uma vez que o processo A fornece uma quantidade suficiente de intermediários e consome a maior parte do $\mathrm{Br}^{-}$, o processo $\mathrm{B}$ passa a dominar. A reação global do processo B é apresentada na Equação 11

$2 \mathrm{BrO}_{3}^{-}+12 \mathrm{H}^{+}+\mathrm{Ce}^{3+} \rightarrow \mathrm{Br}_{2}+6 \mathrm{H}_{2} \mathrm{O}+10 \mathrm{Ce}^{4+}$

O processo B produz $\mathrm{Ce}(\mathrm{IV})$ e $\mathrm{Br}_{2}$ e ambos oxidam o material orgânico, gerando íons brometo. Como a concentração destes íons volta a aumentar, o processo A volta a dominar.

Este experimento foi acompanhado por "Trepak, A Dança Russa" de "O Quebra-Nozes" de Tchaikovsky. O trecho foi selecionado para ser, assim como no caso da reação anterior, fundo musical do baile de cores. Porém, neste caso, como é possível visualizar um número maior de cores, e as mudanças destas cores são mais frequientes, a música escolhida deveria ter um ritmo mais acelerado em relação à música escolhida para a primeira reação oscilante.

\section{Experimento 7. Reação simulando a chuva ácida}

A chuva ácida é um fenômeno que ocorre nas grandes cidades devido à poluição causada pela emissão de óxidos na atmosfera. Este experimento tem como objetivo ilustrar a formação de um dos óxidos ácidos responsáveis pela chuva ácida e a ação desta sobre a vegetação. 
Para este experimento, utilizou-se $50 \mathrm{~mL}$ de uma solução de hidróxido de sódio $0,1 \mathrm{~mol} \mathrm{~L}^{-1}$ em um béquer de $500 \mathrm{~mL}$, juntamente com algumas gotas de indicador fenolftaleína. Em um fio de cobre, prendeu-se um pedaço de papel de tornassol e na ponta uma pétala de flor preferencialmente de coloração vermelha (em nossos experimentos, foram utilizadas pétalas de hibisco). O fio de cobre foi preso na boca do béquer com um elástico. A seguir, colocou-se enxofre em pó até a metade de uma tampinha de garrafa presa por um arame. A seguir levou-se a tampinha ao fogo de uma lamparina, segurando pelo arame e esperou-se o enxofre entrar em fusão. Então, rapidamente colocou-se a tampinha dentro do béquer, fechando-o com papel alumínio. Pode-se observar a formação de uma névoa branca e, depois de 5 min, observar mudanças no papel de tornassol, na solução e na pétala ${ }^{10}$.

A névoa é formada por óxidos de enxofre, que reagem com a água atmosférica para formar ácido sulfúrico. A geração desse ácido é evidenciada pela mudança de cor do papel tornassol, pela neutralização da solução de hidróxido de sódio (que também mudou de coloração devido à presença da fenolftaleína) e pela descoloração da pétala (que indica também um dos efeitos da chuva ácida sobre a vegetação). A música utilizada neste experimento foi "Carmina Burana”, de Carl Orff, por evocar um clima de catástrofe.

As Equações das reações químicas envolvidas no experimento foram:

I - Queima do enxofre:

$\mathrm{S}+\mathrm{O}_{2} \rightarrow \mathrm{SO}_{2}$

II - Transformação do $\mathrm{SO}_{2}$ em $\mathrm{SO}_{3}$ :

$\mathrm{SO}_{2}+1 / 2 \mathrm{O}_{2} \rightarrow \mathrm{SO}_{3}$

III - Reações dos óxidos com água:

$\mathrm{SO}_{2}+\mathrm{H}_{2} \mathrm{O} \rightarrow \mathrm{H}_{2} \mathrm{SO}_{3}$

$\mathrm{SO}_{2}+\mathrm{H}_{2} \mathrm{O} \rightarrow \mathrm{H}_{2} \mathrm{SO}_{4}$

\section{RESULTADOS E DISCUSSÃO}

De acordo com o questionário, três experimentos despertaram maior interesse nos alunos: chuva ácida, reações oscilantes e reação ativada pela voz. Dentre estes, a simulação da chuva ácida foi a que mais se destacou por se tratar de um problema ambiental relacionado ao cotidiano dos alunos e por permitir a associação com os conceitos químicos vistos em sala de aula. No experimento da "simulação da chuva ácida" foi possível visualizar a mudança do sistema, a variação do $\mathrm{pH}$ e os efeitos nas plantas, pois além de descolorir, a planta (hibisco) também murchou, devido à fumaça e ao calor.

As reações oscilantes chamaram a atenção pelo fato da alternância de cores se dar sem interferência direta do experimentador, uma vez que o sistema tinha sua cor alterada diversas vezes, mesmo quando se interrompia a agitação magnética.

No experimento da reação "ativada" pela voz, os alunos eram convidados a pronunciar os seus nomes sobre um erlenmeyer contendo uma solução com um indicador que mudava de cor pela reação com o gás carbônico expelido durante a fala. Desta maneira, os alunos podiam interagir com o experimento, o que tornou essa prática bastante divertida e envolvente. As perguntas mais freqüentes eram: "Por quê com ele (outro aluno) mudou e comigo não?", "E se eu falar bastante?", "Posso falar mais alto?". Neste momento, eram fornecidas aos alunos a explicação e discussão do experimento.
Em seus comentários, os alunos destacaram ainda que os experimentos realizados resgatam o caráter lúdico da experimentação em Química, a ciência da transformação, que para eles era uma disciplina enfadonha que os obrigava a decorar nomes e fórmulas de compostos que, por sua vez, eram nocivos à saúde humana e ao meio ambiente. Ao contrário de suas concepções prévias, muitos deles relataram a constatação de que a Química possui aspectos fascinantes, especialmente devido ao apelo visual de alguns experimentos, conforme se pode observar nas afirmações abaixo:

\footnotetext{
"Esses experimentos foram surpreendentes a ponto de me fazer descobrir uma outra forma de ver a Química e as coisas boas que ela pode oferecer".

“Com a apresentação, a Química passa a ser mais próxima e comum, porque a teoria que a gente vê no colégio esconde tudo o que ela tem de interessante".
}

Além disso, muitos alunos se mostraram surpresos ao constatar que a Química está presente em muitos momentos de suas vidas, especialmente pela utilização de materiais acessíveis em alguns dos experimentos apresentados, tais como detergente e água oxigenada.

"O experimento que eu mais gostei foi o das espumas, porque eu nunca imaginei que a gente pode fazer um experimento tão legal com um produto que é muito fácil de encontrar, o detergente!"

Outro ponto importante a ser destacado é o fato de que $80 \%$ dos alunos disseram nunca ter tido oportunidade de participar de aulas em laboratório, uma vez que muitas escolas não oferecem infra-estrutura necessária para a realização de aulas experimentais. Embora a demonstração de experimentos realizada em nosso projeto não tenha a mesma finalidade pedagógica das atividades realizadas em laboratório, nas quais ocorre uma participação mais efetiva dos alunos, esse tipo de atividade pode ser uma alternativa para a falta de laboratórios nas escolas.

Outro ponto a ser destacado é que essa foi uma oportunidade em que os alunos puderam se aproximar da música clássica, já que muitos deles não têm acesso a esse tipo de atividade cultural. Podemos ressaltar, ainda, que as músicas que acompanhavam os experimentos constituíram outro fator capaz de sensibilizar a percepção, criando um ambiente favorável à assimilação das explicações dos fenômenos químicos envolvidos nos experimentos apresentados. Isso é demonstrado por expressões utilizadas pelos alunos como "as músicas criaram um clima de suspense" ou "as músicas ajudam na concentração para entendermos o que está acontecendo". Durante e ao final da realização dos experimentos, os alunos puderam perceber como a Química desvenda o aparente "mistério" em torno dos fenômenos observados, utilizando as explicações provenientes de suas teorias.

\section{CONCLUSÕES}

As atividades apresentadas neste artigo mostram-se extremamente eficientes na divulgação da Química entre alunos do ensino médio e fundamental, bem como para alunos ingressantes no curso de Química.

A exibição de experimentos demonstrativos com o auxílio de trilhas sonoras é uma maneira informal de comunicação da química com o público alvo, privilegiando a imaginação e a criatividade em seus aspectos sensoriais e emocionais. Na realidade, a informação química foi trabalhada de maneira prazerosa por estarmos tratando de percepção e memória visual e auditiva. Essas características do audiovisual nos fornecem pistas para organizar ativida- 
des em sala de aula que comecem pelo sensorial, pelo afetivo, pelo que toca o aluno, antes de falar de idéias, de conceitos, de teorias. Partir do concreto para o abstrato, do imediato para o mediato, da ação para a reflexão, da produção para a teorização ${ }^{11}$.

Neste tipo de atividade, pode-se observar que experimentos demonstrativos despertam as habilidades de observação e envolvem os alunos, chamando a atenção pela sensibilidade. Cabe ao professor mediar a assimilação do conhecimento vinculado a cada experimento.

Além da excelente receptividade demonstrada, muitos alunos passaram a considerar a Química como uma possível escolha profissional.

\section{AGRADECIMENTOS}

À Comissão de Cultura e Extensão Universitária do IQSC-USP, ao CNPq, à CAPES, à FAPESP e ao Centro de Divulgação Científica e Cultural da USP - São Carlos.

\section{REFERÊNCIAS}

1. Babin, P.; Koulumdjian, M.; Os novos modos de compreender - Geração do audiovisual e do computador, Ed. Paulinas: São Paulo, 1989.

2. Arroio, A.; Giordan, M.; Quim. Nova na Escola, submetido.

3. Giordan, M.; Quim. Nova na Escola 1999, $n^{\circ} 10,43$.

4. Vanin, J. A.; J. Chem. Educ. 1991, 68, 652.

5. Shakhashiri, B. Z.; Chemical Demonstrations, The University of Wisconsin Press: Madison, 1985, vol. 2.

6. Shakhashiri, B. Z.; Chemical Demonstrations, The University of Wisconsin Press: Madison, 1983, vol. 1.

7. In memorian; Quim. Nova 2001, 24, 574.

8. Carneiro, C.; Criatividade e Cérebro, Ed. Ponto e Vírgula: Salvador, 2004.

9. Vygotsky, L. S.; Pensamento e Linguagem, Martins Fontes: São Paulo, 1991.

10. http://www.cdcc.sc.usp.br/quimica/experimentos, acessada em Agosto 2004.

11. Morin, Edgar.; Os sete saberes necessários, Bertrand Brasil: Rio de Janeiro, 1995. 